The sooner the premonitory diarrhce is stopped, and the earlier our resources can be brought to bear, the less every where becomes the mortality. We believe the fact to be indubitable, not only from Indian, but from European statistics; and the more men's minds are enlightened as to the necessity of sanitary measures, and the removal of nuisances, the better chance we have in arresting the progress of the formidable epidemic. It is not only thus with cholera, but with all other epidemic diseases. Filth of all kinds appear to be the appropriate soil or nidus of contagion. Fresh air, ventilation, and cleanliness, moderate the virulence of every febrile disease; so that we could almost pardon the exclusive attention which even our sanitary com. missioners appeur to have given to this element of the question, if truth did not demand a more candid avowal. The facts proving the cholera to be contagious or communicable from infacted sources we deem to be irrefragable, but the rapid dissemination of that con. tagion which appears sometimes to have extended a very considerable distance from the primary source, and carried on the wings of the wind and along the banks of rivers, often baffles quarantine regulations, and has often leuped the barriers of the "cordon sanitaire." We do not imagine the infection exists in a great degree in the stage of collapse, but the consecutive fever, and the facal evacuations, seem to be sources of the poison. The mouths of sewers, the low swamps bordering rivers, and the long occupied ground of camps, are always dangerous positions to inhabit, but when the disease has already made its appearance, are tenfold more hazardous. In the belief of its contagion, care should be taken to destroy or otherwise purify, by chlorine and afterwards boiling water, the bed-clothes and under garments of those who have been affected with the disease. The history of cholera shews us, for our comfort, that it cannot permanently take up its abode with us as it has done in India. It will die out after a short time; it is not like the smallpox and typhus fever, one of the indigenous or naturalized diseases of our climate. It is a foreign exotic, and the great majority of our northern constitu. tions are not susceptible of the disease in its most malignant form. It is, then, a transient epidemy; it now re-appears after an absence of nearly sixteen years. By a careful study of its laws of propagation, as well as the best means of alleviating its sufferings, we shall be fulfilling our high duty. The mercantile world may hug its delusions, which "Boards of Health" and leading articles in the Times may please to foster, but the medical profession will not sacrifice the truth of any well-established conclusion on the mere ipse dixit of a few zealous partisans. We know the infection of small-pox was not noticed by ancient observers, and the contagion of the plague has been denied by modern writers; we are prepared, therefore, for the most broad assertions with regard to cholera. Facts, howerer, are stubborn things, and there is a force in truth which at length overcomes all fallacies.

\section{ON TAE}

\section{TREATMENT OF RHEUMATIC PARALYSIS BY FLECTRO-MAGNETISM.}

\author{
By William Davies, M.D., Physician to the Bath \\ United Hospital.
}

(Read at the Bath and Bristol Branch of the Prorincial Medical and Surgical Association.)

\section{Mr. President, -}

I purpose, on the present occasion, to bring under your notice the case of an individual who had suffered for many months under rheunatic paralysis of the hands and lower extremities, and in whom power over her limbs became restored under the use of electrogalvanism.

I will, in the first place, detail the case, and, secondly, offer a few fragmentary remarks on the agent employed in the cure,-namely, electricity, in its relation to living beings.

\section{CAsE.}

Jane Farley, aged 25, had always enjoyed good bealth; had been accustomed to work in a laundry, in which occupation she was much exposed to cold and damp. Previously to the illness of which I am about to speak, she had never suffered from rheumatism. In December, 1845, her hands began to swell, and she gradually lost the power of using thein, but suffered very little pain. The swelling and weakness continued to increase until February, at which time she was admitted into the United Hospital, under the care of Dr. Bealy. She remained under treatment eight weeks, when she was discharged greatly relieved, the swelling of the bands being much diminished, and the power almost restored. She returned to her occupation of laundress. The improvement was only of three weeks' duration, when the affection of the hands returned, accompanied at this time with swelling, pain, and weakness of the feet and knees.

In August, 1846, she first came under my care as an out-patient of the United Hospital. At this time she was in the following condition:-The joints of the hands, feet, and knees, much swollen, and exquisitely painful to pressure. She was unable to walk across a room without assistance, and she had so little use of her hands, as to be unable to dress and undress herself without aid. Her skin was covered with a cold clammy moisture, of a sour odour, and a strongly acid reaction on litmus paper. She suffered nuch from irritability of the stomach and bowels, in the form of acid eructations and diarrhœa; there was considerable epigastric pain and tenderness, especially after taking food; the ongue was red and pointed, the papillæ at the point being large and prominent; the organ was also covered here and there with thin patches of creamy exudation, through which the red raw-looking mucous surface could be distinctly seen. The pulse was quick, and of sinall volume; menstruation was rather profuse.

The treatment at this time consisted chiefly of sedatives and antacids. She seemed to derive more benefit from a mixture of hydrocyanic acid and bicarbonate of potass in water, than from any other remedy tried; she took four minims of the one, and 
ten grains of the other, every four or six hours, according to circumstances. Under this treatment her general health improved exceedingly, and she got rid of the troublesome gastric symptoms nnder which she had laboured at the commencement, but the power over her limbs remained very much in statu quo.

On the 9th of October, I admitted her as an inpatient, and she remained in the hospital nine weeks. She was only, however, under iny observation the first two weeks of that period, in consequence of my being confined to the house through indisposition, during the remainder of the time; I therefore pass over that period, merely observing that she left the hospital with even less power over her limbs than she possessed on her admission. On quitting the hospital, in the second week in December, she took to her bed, from which she did not move otherwise than as she was lifted, until the 5th of March, 1847, when I again admitted her as an in-patient of the hospital. Her condition at this time was much the same as I have already described, except that she had totally lost all power over her limbs. She was unable to stand without assistance, and could not hold anything in her hands. She remained in the hospital fourteen weeks, during which time she was subjected to various treatment, the details of which would occupy too much of the time of the meeting; this, I may say, however, that each step of the treatment was adopted after as careful consideration as I was able to bestow upon the case. The common warm bath, and subsequently the vapour bath, were fairly tried; from the use of the latter she derived some benefit, was able, at the time she left the hospital, to stand without assistance, and even, on first rising from bed, to walk a few yards with the aid of some object on which to rest her hands. Her general health at this time was much improved.

From the middle of June, the time of her quitting the bospital, until the first week in August, she remained with her friends in a most helpless condition, quite unable to do anything for herself; she was then removed to an apartment near the hospital, with the view of trying the effect of galvanism in the warm bath. She was galvanized in the bath daily, with few exceptions, for a fortnight, at the end of which time she was able to walk from the place where she lodged to the hospital, and back again, a distance of 300 or 400 yards, an exploit she had not previously performed for more than eighteen months. At this time the application of the galvanism was arrested for a montb, in consequence of the great inconrenience attending its use in the common slipper bath,-the only one at my disposal. During that month she retrograded to nearly her former condition, being unable to do more than walk across a room, and that not without difficulty and with support. On the 23rd of September, I was enabled again to have recourse to galvanism, in a bath admirably adapted for the purpose, through the kindness of Messrs. Green and Simm, the lessees of the baths. From this date she was galvanized daily, with the exception of the Sundays, for two months, during which time sle improved gradually but rapidly, until it was considered no longer necessary to continue the treatment, from her recovery being complete. I am indebted to Mr. Tyler, chemist, of this city, for having taken off my hands the troublesome and laborious office of applying the galvanism. The apparatus used was the ordinary electro-galvanic. The application was continued at first for a quarter of an hour, but subsequently, during half an hour. She took no medicine of any kind while under treatment by galvanism.

I fear, sir, you will consider that I have been tediously minute in the relation of this case, but it seems to me an interesting and important one, and $I$ think it advisable, whenever a case is adduced in support of the efficacy of any particular therapeutic agent, or line of practice, that the observer should state the case minutely, 80 as to place those who may hear or read it, as far as may be, in the same position as he is himself, in respect of forming a judgment as to the truth or error of the conclusion which the author has been led to form.

It is proper to call the attention of the Society to one point in the relation of the case, which seems to me to remove any doubt which might exist, as to whether galvanism really was the efficacious cause of cure, or only a mere co-incident. 1st. It could not have heen the warm bath alone which brought about the cure, as full triat had been given it under similar circumstances previously, without any appreciable benefit. 2nd. That it was the galranism, is proved by this; that under the first fortnight's application, great improvement took place; that all this improvement was lost during a montli's suspension of the treatment, and that on its resumption improvement was again manifested, which went on under its continuance to a perfect cure.

The patient has returned to her occupation of ironer for more than three months, and now stands at her work during twelve hours a day, six days in the week By the evening her feet become somewhat painful and swollen, as also her hands, but she told me within the last week that she was quite well, and that if she had it in her power to follow any occupation that did not involve so much standing; she slould be as well as ever she was.

The above case illustrates sufficiently well the therapeutic influence of electricity in one form of disease,-namely, rheumatic paralysis of the muscles of the extremities, the great nervous centres remaining intact, and that this is the particular form under which we ought to expect benefit to arise from the use of electricity, perhaps, more than under any other, will, I think, appear from a short review of what we know concerning this agent, in its relations to living beings.

Professor Matteucci, of Pisu, towhom we are indebted for nearly all the precise knowledge we possess on this subject, has shewn that there is a constant current of free electricity traversing the muscles of all animals, even of man himself; - that the course of the current is from within outwards; - that the higher the animal is in the scale of being, the greater is the amount of electricity developed;-that any cause which has the effect of reducing the vital power of an animal, and impairing its due nourishment, diminishes proportionately to the extent of change, the intensity of the muscular current;-that immersion of an animal in 
sulphureted hydrogen gas destroys the current altogether, and, on the other hand, that anything which tends to increase the development of muscular power, increases also the electric current in those muscles.

It has been observed by Pfaff and Abrens, and also by Humboldt, as will appear froin the following quotation from "Müller's Physiology," that in rheumatic affections the electricity of the body is at zero. They say :- "During the continuance of rheumatic affections the electricity of the body seems to be reduced to zero, and to become manifest again as the disease subsides. It appears to $\mathrm{Humboldt}$ also, that rheumatic patients had an insulating action on the feeble current produced by a simple galvanic circle."

It has been shewn that muscles lose their power of contraction when the current of blood towards them is obstructed; this has been observed in the human subject after ligature of a large arterial trunk in the muscles supplied by that vessel, and also in the hinder extremities of animals after ligature of the abdominal aorta. Müller, speaking of the influence of the blood on the contraction of muscles says, - "It is therefore certain that the arterial blood undergoes in the motor organs, a change, which, while it gives the blood the venous character, renders it unfit to maintain in the muscles their contractile property,-in other words, that the property of contractility requires for its perfect preservation the constant action of arterial blood on the muscular fibre."

Now, Davy and Faraday, among their numerous additions to physical science, have proved this-that wherever chemical action takes place, there free electricity is produced; in fact, that chemical affinity and electricity are identical powers. Liebig has shown that if fresh muscular tissue be cut small, and macerated in distilled water, it gives an acid reaction on litmus paper, and this, notwithstanding the large quantity of alkaline blood contained in its ressels, thus proving a secretion from the capillaries of an acid nature; so that in muscles there exists an alkaline fluid within the ressels, and an acid fluid without, a moist animal membrane interrening, - a condition of matters which has been abundantly proved capable of producing chemical action, and, consequently, of setting free electricity.

Now, frum what has been said it has been shown :-

1st. That there is in all muscles a constant current of free electricity.

2ad. That the intensity of the muscular current bears a direct ratio to the vigour of the animal, and the degree of development of the muscular structure.

3rd. That immersion of an animal in sulphuretted bydrogen gas destroys the current altogether.

4th. That in rheumatic affections, the electricity of the body is at zero, but becomes manifest again as the disease subsides.

5th. That a constant supply of arterial blood is essential to the contractile power of muscles.

6tk. That wherever there is chemical action, free electricity is developed.

7ths That the conditions of chemical action exist in muscles, by means of the alkaline fluid within, and the acid finid without the ressels.
Analogous to this last head, and confirmatory of its truth, is an experiment performed by Aldini, at Fuy's Hospital, in 1803, in which he took the prepared leg of a frog, and held the extremity in his hand, previously well moistened with salt and water, while he allowed the free end of the sciatic nerve to touch his tongue; contractions of the muscles of the frog's leg were immediately produced, thus proving the existence of an electric current passing between the internal and external surface of his body. See, for further details, Dr. Bird's "Natural Philosophy," or his lectures before the College of Physicians, in 1847, published in the Medical Gazette. Donné, in the "Ann. des Sciences Nat." for February, 1834, gave the explanation of this experiment, by referring it to the different chemical conditions of the integument of the body, and the mucous covering of the alimentary canal,-the one being acid, and the other, for the most part, alkaline, meeting at the mouth, nostrils, and anus. It will be seen that this condition is similar to what has been already mentioned as existing in muscles.

Now, if we keep before us the various facts $I$ bave adduced, and venture on an attempt at their estimation, the following may, perhaps, appear not altogether unreasonable :-

1st. We have the fact of a constant electric current in the muscles of all animals. What are the conditions which diminish this current? 1. A low position in the scale of living beings. 2. Imperfect development of the muscular structure, with depressed vital powers. 3. Immersion of an animal in sulphuretted hydrogen gas. 4. A rbeumatic condition of the system. All, (it will be observed,) circumstances in which the free action between the arterial blood, and the muscular fibre, is either interfered with or destroyed, and all circumstances which impair the contractile power of muscles.

2ndly. What are the conditions which increase this current? Everything that is the opposite of the above ; high vital powers, full development of the muscular structure, in fact everything that promotes the free action between the arterial blood and the muscular fibre,-everything that is essential to powerful muscular contractions.

These facts seem to point to a very close relation between muscular contractility and electricity, if they do not go far enough to shew that the one stands to the other in the relation of cause and effect; and they certainly furnish a very strong theoretical reason, anterior to all experiential evidence, in favour of electricity as a remedial agent in certain forms of impaired muscular contractility.

It would be irrelevant to the matter in hand to enter into other relations which probably exist between electricity and vital actions, besides which we should be in danger of losing ourselves in the mists of speculation; this, however, I may be allowed to say, that I believe no department of science offers to the medical philosopher a more worthy subject of study than that which I have attempted to bring under your notice this. morning. 